\title{
TINJAUAN PROSEDUR PEMBELIAN BARANG DI BAGIAN PURCHASING PADA PT. DURACONINDO PRATAMA JAKARTA
}

\author{
Heri Aryadi ${ }^{1}$, Wahyuni ${ }^{2}$ \\ Akademi Sekretari dan Manajemen BSI Jakarta \\ heriaryadi75@gmail.com $^{1}$
}

\begin{abstract}
Abstrak - Pembelian merupakan suatu usaha yang dilakukan untuk pengadaan barang yang diperlukan oleh perusahaan. Persediaan bahan baku merupakan faktor utama dalam perusahaan untuk menunjang kelancaran proses produksi. Metode yang digunakan dalam penelitian jurnal ini adalah dengan observasi yaitu melakukan pengamatan secara langsung terhadap kegiatan prosedur pembelian barang di bagian purchasing pada PT. Duraconindo Pratama Jakarta. Kemudian wawancara yaitu dengan mengajukan beberapa pertanyaan kepada pihak purchasing yang ada di PT. Duraconindo Pratama Jakarta dengan pertanyaan yang berhubungan dengan materi yang dalam jurnal ini. Selanjutnya dengan metode studi pustaka, yaitu dengan mencari referensi buku-buku yang mengacu pada bidang yang berkaitan dengan objek penelitian. Hasil dari penelitian ini adalah prosedur pembelian barang di PT. Duraconindo Pratama sudah berjalan dengan baik namun terdapat kendala seperti barang yang diterima tidak sesuai PO akan tetapi kendala tersebut diatasi dengan mengembalikan barang kepada pihak supplier dan diganti sesuai dengan PO yang dikeluarkan.
\end{abstract}

\section{Kata Kunci: Pembelian, Prosedur Pembelian}

\begin{abstract}
Abstrak Purchasing is a business who did for goods procurement that needed by company. Stock of raw materials is a primary factor who needed by company to supporting their production process. Method that used by authors to preparation this jurnal are by doing directly observation for procedure of goods procurement in division purchasing at PT. Duraconindo Pratama Jakarta. And then author make an interview with some staffs of purchasing in PT. Duraconindo Pratama Jakarta with ask some questions related with material that author's propose. After that by using method of literature reviews by searching for reference books who referring or related with object of research. The result of research for goods procurement procedure in PT. Duraconindo Pratama Jakarta has gone well but there are some constraints like goods received are unmatch with $\mathrm{PO}$ but that constraint can solved by restore the goods to supplier and requesting a goods that matching with PO.
\end{abstract}

\section{Keywords: Purchasing, Purchasing Procedure}




\section{PENDAHULUAN}

Pembelian merupakan suatu usaha yang dilakukan untuk pengadaan barang yang diperlukan oleh perusahaan. Kegiatan pembelian ini merupakan salah satu fungsi dasar sebuah perusahaan, karena suatu perusahaan tidak akan dapat beroperasi dengan baik tanpa pengelolaan pembelian yang benar dan sesuai dengan prosedur. Pembelian tersebut timbul akibat adanya permintaan barang yang akan diproduksi untuk menghasilkan suatu output untuk mendapatkan laba.

Menurut Cahyo dan Solikhin pembelian atau purchasing adalah proses penemuan sumber dan pemesanan bahan, jasa, dan perlengkapan, kegiatan tersebut terkadang disebut pengadaan barang".

Pada dasarnya peran fungsi pembelian adalah untuk menyediakan barang dan jasa yang dibutuhkan oleh perusahaan pada waktu, harga dan kualitas yang tepat. Dan untuk mencapai tahap pembelian tentunya ada serangkaian proses-proses yang terjadi di belakang sebelum sampai pada proses pembelian seperti kebutuhan-kebutuhan dasar produksi yang sebelumnya sudah diperkirakan oleh departemen produksi. Pentingnya pembelian ini menjadi fokus penting dan berpengaruh bagi setiap perusahaan, dan bila perusahaan sudah masuk ke dalam skala besar biasanya pembelian menjadi suatu proses yang sangat rumit dan harus dikendalikan dengan benar karena berkaitan dengan kas perusahaan.

Menurut Indrajit dalam jurnal (Prayunantyo \& Supriono, 2017) Kebijakan adalah suatu pernyataan yang memberikan gambaran secara umum mengenai arah pelaksanaan suatu tindakan. Kebijakan adalah semacam pedoman umum mengenai pelaksanaan tugas pembelian. Indrajit mengklasifikasikan kebijakan pembelian menjadi 2 faktor, diantaranya:

1. Kebijakan Internal

Kebijakan yang bersifat internal biasanya menyangkut hal-hal seperti apakah pembelian dilakukan dengan sistem sentralisasi atau tersebar, apakah pembelian dilakukan sendiri (insourcing) atau diserahkan ke perusahaan lain (outsourcing), apakah pembelian dilakukan ke luar negeri atau dari sumber dalam negeri, dan sebagainya.

2. Kebijakan Eksternal 
Kebijakan eksternal meliputi hal-hal seperti bagaimana hubungan antara penjual dan pembeli, apakah atas dasar incidental berjangka pendek atau atas kemitraan berjangka panjang, apakah permintaan penawaran berdasarkan penunjukan langsung atau tender terbuka atau tender terbatas, dan sebagainya.

Persediaan bahan baku merupakan faktor utama dalam perusahaan untuk menunjang kelancaran proses produksi, baik dalam perusahaan besar maupun kecil. Kesalahan menentukan besarnya investasi dalam mengontrol bahan baku yang terlalu besar dibandingkan kebutuhan perusahaan akan menambah beban bunga, biaya pemeliharaan dan penyimpanan dalam gudang, serta kemungkinan terjadinya penyusutan dan kualitas yang tidak bisa dipertahankan, sehingga semuanya ini akan mengurangi keuntungan perusahaan. Demikian pula sebaliknya, persediaan bahan baku yang terlau kecil dalam perusahaan akan mengakibatkan kemacetan dalam produksi, sehingga perusahaan akan mengalami kerugian juga.

Perumusan masalah dalam penelitian ini adalah:

1. Bagaimana prosedur pembelian barang di bagian purchasing pada PT. Duraconindo Pratama Jakarta?

2. Apa saja kendala-kendala yang dihadapi dalam melakukan pembelian barang di bagian purchasing pada PT. Duraconindo Pratama Jakarta?

3. Bagaimana cara mengatasi kendala-kendala yang dihadapi dalam melakukan pembelian barang di bagian purchasing pada PT. Duraconindo Pratama Jakarta?

Adapun tujuan dari penelitian ini adalah:

1. Untuk mengetahui prosedur pembelian barang di bagian purchasing pada PT. Duraconindo Pratama Jakarta?

2. Untuk mengetahui kendala-kendala yang dihadapi dalam melakukan pembelian barang di bagian purchasing pada PT. Duraconindo Pratama Jakarta?

3. Untuk mengetahui cara mengatasi kendala-kendala yang dihadapi dalam melakukan pembelian barang di bagian purchasing pada PT. Duraconindo Pratama Jakarta? 


\section{LANDASAN TEORI}

Standard Operating Procedure atau disingkat SOP biasanya dijadikan standar bagi pelaksanaan prosedur kerja tertentu. Sehingga, banyak juga yang menyebutnya sebagai "prosedur" atau dalam bahasa Indonesia diterjemahkan sebagai prosedur operasional standar. Dalam KBBI prosedur diartikan sebagai tahap kegiatan untuk menyelesaikan suatu aktivitas, atau metode langkah demi langkah secara pasti dalam memecahkan suatu masalah.

Menurut Soemohadiwidjojo (2017:90) mendefinisikan bahwa "Standard Operating Procedure (SOP), atau disebut juga sebagai prosedur adalah dokumen yang lebih jelas dan rinci untuk menjabarkan metode yang digunakan dalam mengimplementasikan dan melaksanakan kebijakan dan aktivitas organisasi seperti yang ditetapkan dalam pedoman”.

Selanjutnya menurut Arina (2016:31) mengemukakan bahwa "Standard Operating Procedure (SOP) atau yang biasa disebut prosedur adalah serangkaian instruksi kerja tertulis yang dibakukan (terdokumentasi) mengenai proses penyelenggaraan administrasi perusahaan, bagaimana dan kapan harus dilakukan, dimana dan oleh siapa dilakukan".

Pendapat lain menurut Mulyadi dalam jurnal (Dewi \& Wiyani, 2016) menyatakan bahwa "Prosedur adalah suatu urutan kegiatan klikeral biasanya melibatkan beberapa orang dalam satu departemen atau lebih yang dibuat untuk menjamin penanganan secara seragam transaksi perusahaan yang terjadi berulang-ulang”.

Adapun menurut Atmoko dalam Arina (2016:31) menyatakan bahwa "SOP merupakan suatu pedoman atau acuan untuk melaksanakan pekerjaan sesuai dengan fungsi dan alat penilaian kinerja instansi pemerintah berdasarkan indikator-indikator teknis, administratif dan prosedural sesuai dengan tata kerja, prosedur kerja dan sistem kerja pada unit kerja yang bersangkutan".

Dari beberapa pendapat ahli diatas maka penulis menyimpulkan bahwa prosedur adalah serangkaian tatacara kerja atau kegiatan yang melibatkan beberapa orang untuk menyelesikan pekerjaan dengan cara-cara yang telah ditentukan. 
Menurut Sutarman (2017:135) menyatakan bahwa "Pembelian atau purchasing adalah kegiatan esensi dalam berbagai bentuk organisasi manufaktur, non-manufaktur, yang berorientasi laba, nirlaba, maupun sektor pemerintahan".

Pendapat lain menurut (Cahyo \& Solikhin, 2017) "Pembelian atau purchasing adalah proses penemuan sumber dan pemesanan bahan, jasa, dan perlengkapan, kegiatan tersebut terkadang disebut pengadaan barang”.

Adapun menurut Himayati dalam jurnal (Fatkhudin, 2018) "Pembelian adalah suatu transaksi dimana perusahaan membutuhkan barang atau jasa, baik untuk dipakai maupun untuk persediaan yang akan dijual".

Sedangkan menurut Assauri dalam jurnal (Hidayat \& Witjaksono, 2017) "Pembelian atau purchasing adalah salah satu fungsi yang sangat penting dalam berhasilnya suatu dalam perusahaan. Fungsi yang bertanggung jawab untuk mendapatkan kuantitas dan kualitas bahan-bahan yang tersedia dalam waktu yang dibutuhkan dengan harga yang sesuai dan dengan harga yang berlaku”.

Menurut (Sholikhah, Sairan, \& Syamsiah, 2017) "Pembelian atau purchasing adalah akun yang digunakan untuk mencatat semua pembelian barang dagangan dalam satu periode".

Dari beberapa pendapat ahli diatas maka penulis menyimpulkan bahwa pembelian adalah suatu usaha yang dilakukan untuk pengadaan barang yang diperlukan oleh perusahaan.

\section{METODE PENELITIAN}

Penelitian ini dilakukan di PT. Duraconindo Pratama Jakarta. Penelitian dilakukan menggunakan metode kualitatif dengan melakukan observasi secara langsung yang bertujuan untuk mengumpulkan data dan informasi yang lengkap.

Selain observasi, penulis juga melakukan wawancara secara langsung dengan pihak yang terkait mengenai prosedur pembelian barang di bagian purchasing pada PT. Duraconindo Pratama Jakarta agar memperoleh data dan informasi yang akurat. Wawancara ini penulis tujukan kepada narasumber yaitu Bapak Aditya Faryanto bagian purchasing pada PT. Duraconindo Pratama. 
Penulis juga menggunakan buku-buku sebagai referensi untuk mencari landasan teori dan pendapat dari para ahli terkait pembahasan penelitian ini selain data yang didapat dari kantor PT. Duraconindo Pratama Jakarta.

\section{HASIL ANALISIS DAN PEMBAHASAN}

Pembelian barang merupakan hal terpenting bagi perusahaan manufaktur seperti PT. Duraconindo Pratama dalam memenuhi kebutuhan bahan baku. Dengan terpenuhinya kebutuhan baku, proses produksi pun dapat berjalan dengan lancar dan permintaan produk precast yang telah dipesan oleh konsumen dapat terkirim sesuai schedule/jadwal. Sesuai motto yang ada pada PT. Duraconindo Pratama adalah produk berkualitas dan pengiriman tepat waktu.

Berdasarkan data yang didapat dari hasil penelitian yang telah dilaksanakan pada bagian purchasing PT. Duracoindo Pratama, maka prosedur pembelian barang bulan April 2018 dapat dilihat pada tabel dibawah ini.

Tabel 1. Prosedur Pembelian Barang PT. Duraconindo Pratama

\begin{tabular}{|c|l|l|}
\hline No. & \multicolumn{1}{|c|}{ Proses } & \multicolumn{1}{c|}{ Keterangan } \\
\hline 1. & $\begin{array}{l}\text { Menerima daftar permintaan } \\
\text { barang }\end{array}$ & $\begin{array}{l}\text { Sebelum terjadinya proses pembelian barang, bagian purchasing } \\
\text { terlebih dahulu menerima surat permintaan barang dari pabrik } \\
\text { PT. Duraconindo Pratama. }\end{array}$ \\
\hline 2. & Pemilihan supplier. & $\begin{array}{l}\text { Proses ini terjadi sesuai dengan kebutuhan pabrik, untuk } \\
\text { memenuhi stok bahan baku apa saja yang dibutuhkan. }\end{array}$ \\
\hline 3. & $\begin{array}{l}\text { Pengajuan permintaan } \\
\text { penawaran harga. }\end{array}$ & $\begin{array}{l}\text { Sebelum terjadinya proses pembuatan PO, pihak purchasing } \\
\text { akan terlebih dahulu melakukan/membuat surat permintaan } \\
\text { penawaran harga. }\end{array}$ \\
\hline 4. & $\begin{array}{l}\text { Seleksi supplier berdasarkan } \\
\text { kualitas dan harga. }\end{array}$ & $\begin{array}{l}\text { Proses ini terjadi ketika pihak purchasing mendapatkan surat } \\
\text { penawaran harga yang telah diberikan pihak supplier, dan } \\
\text { bagian purchasing menyeleksi supplier mana yang akan dipakai } \\
\text { berdasarkan kualitas barang dan harga. }\end{array}$ \\
\hline 5. & $\begin{array}{l}\text { Pengeluaran } \\
\text { pembelian (purchase order). }\end{array}$ & $\begin{array}{l}\text { Setelah melakukan beberapa tahap yang telah dilakukan bagian } \\
\text { purchasing, PO (purchase order) lalu dibuat setelah dipilihnya } \\
\text { supplier yang telah lolos seleksi berdasarkan kualitas dan harga. }\end{array}$ \\
\hline \multirow{2}{*}{ pesanan }
\end{tabular}


Berikut alur proses pembelian barang di bagian purchasing pada PT. Duraconindo Pratama Jakarta.

\section{Gambar 1. Alur Proses Pembelian Barang}

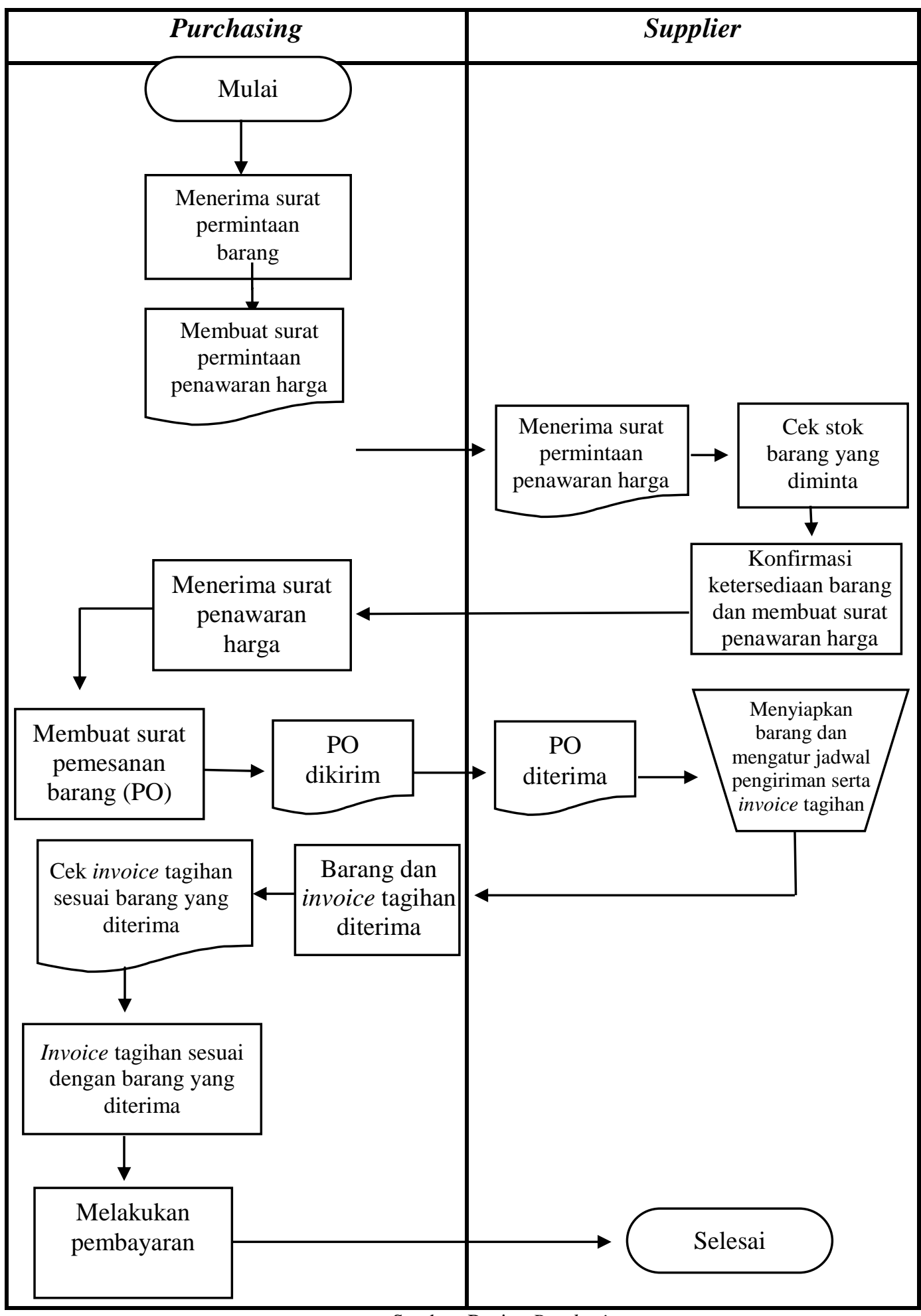

Sumber: Bagian Purchasing 
Keterangan untuk gambar 1. mengenai alur proses pembelian barang adalah sebagai berikut:

1. Bagian purchasing menerima surat permintaan pembelian barang untuk bahan baku dari pabrik.

2. Kemudian bagian purchasing membuat surat permintaan penawaran harga dan dikirim kepada pihak supplier melalui email.

3. Pihak supplier menerima email mengenai permintaan penawaran harga dari bagian purchasing PT. Duraconindo Pratama.

4. Pihak supplier mengecek stok barang yang akan dipesan oleh PT. Duraconindo Pratama sebelum melakukan pembuatan surat penawaran harga.

5. Pengecekan stok barang yang dipesan sudah oke, lalu menyiapkan pembuatan surat penawaran harga dan mengkonfirmasi pihak konsumen serta mengirimkan surat penawaran harga melalui email.

6. Bagian purchasing menerima surat penawaran harga yang dikirim oleh pihak supplier untuk ditindaklanjuti.

7. Kemudian bagian purchasing melakukan pembuatan PO (purchase order) dan dikirim melalui email ke pihak supplier.

8. Pihak supplier menerima PO (purchase order) dan menyiapkan barang yang telah dipesan oleh konsumen, serta mebuat invoice tagihan. Setelah semua oke, barang dikirim sesuai jadwal yang telah disepakati kedua belah pihak.

9. Bagian purchasing menerima barang yang telah dipesan beserta invoice tagihan.

10. Bagian purchasing melakukan pengecekan barang yang telah diterima apakah sesuai dengan PO (purchase order) yang telah dikirim melalui email.

11. Bagian purchasing melakukan pengecekan invoice apakah sesuai dengan barang yang diterima

12. Bagian purchasing melakukan pembayaran atas barang yang telah dipesan dan diterima melalui bank.

Anggaran pembelanjaan pada PT. Duraconindo Pratama tidak ditentukan berapa nominal yang disediakan, akan tetapi ketika dalam pembelanjaan ada kenaikan harga bahan baku maka pihak purchasing menginfokan kepada pihak terkait mengenai kenaikan harga bahan baku tersebut agar pihak marketing maupun sales dapat menyesuaikan harga barang yang akan dipsarkan demi mendapatkan keuntungan. 
Bagian purchasing mendapatkan bahan baku berdasarkan daftar supplier yang telah dimiliki oleh PT. Duraconindo Pratama, yang sebagian besar data supplier tersebut didapat dari website. Kemudian purchasing memilih supplier berdasarkan permintaan dalam pembelian barang. Untuk proses selanjutnya purchasing menyeleksi beberapa supplier berdasarkan kualitas dan harga sebelum terbuat nya PO (purchase order). Cara pembayaran yang digunakan bagian purchasing adalah melalui transfer bank.

Dari analisis data yang telah dilakukan, ada beberapa kendala yang dihadapi bagian purchasing dalam melakukan pembelian barang adalah:

1. Schedule pengiriman yang terlambat.

Keterlambatan pengiriman dari supplier sangat berpengaruh pada kegiatan produksi. Kendala ini terjadi biasanya disebabkan oleh gangguan teknis yang dialami pihak supplier seperti rusaknya forklift untuk memuat barang ke truk, sehingga menyebabkan keterlambatan dalam pengiriman.

2. Barang tidak sesuai PO dan invoice yang diterima.

Kendala ini terjadi disebabkan oleh kesalahan yang dilakukan oleh pihak supplier karena ketidaktelitian dalam melakukan pengecekan barang yang telah dipesan sebelum dikirim. Karena pada kenyataannya barang yang dikirim tidak sesuai dengan PO dan invoice yang diterima.

Cara mengatasi kendala-kendala yang dihadapi bagian purchasing dalam melakukan pembelian barang adalah:

1. Masalah ini menjadi hal yang perlu diperhatikan oleh perusahaan karena akibatnya sangat berpengaruh besar terhadap perusahaan. Solusi dalam mengatasi schedule pengiriman yang terlambat adalah menekankan kepada pihak supplier agar lebih ditingkatkan mengenai jadwal pengiriman barang yang telah ditentukan demi kelancaran kerja sama dalam proses pembelian.

2. Solusi dalam mengatasi kendala ini adalah mengembalikan barang dan mengkonfirmasi kepada pihak supplier. Karena dalam pembuatan PO sudah dijelaskan dan disepakati jika barang yang dikirim tidak sesuai dengan kriteria dan PO yang telah dibuat maka barang akan dikembalikan, dan selanjutnya proses pembayaran akan dijalankan setelah barang tersebut diganti sesuai dengan PO yang telah dikeluarkan. 


\section{PENUTUP}

\subsection{Kesimpulan}

Berdasarkan hasil penelitian dan pembahasan tentang prosedur pembelian barang di bagian purchasing pada PT. Duraconindo Pratama Jakarta, maka dapat diambil kesimpulan sebagai berikut:

1. Prosedur pembelian barang di bagian purchasing pada PT. Duraconindo Pratama sudah cukup baik akan tetapi masih ada sedikit kekurangan dalam proses pembayaran yang seharusnya dilakukan oleh bagian finance justru dilakukan sendiri oleh bagian purchasing. Hal tersebut terjadi karena kurangnya sumber daya manusia pada perusahaan tersebut.

2. Prosedur pembelian barang di bagian purchasing pada PT. Duraconindo Pratama ada beberapa tahap, yaitu:
a. Menerima daftar permintaan barang.
b. Pemilihan supplier.

3. Prosedur pembelian barang di bagian purchasing pada PT. Duraconindo Pratama sudah cukup baik akan tetapi masih ada sedikit kekurangan dalam proses pembayaran yang seharusnya dilakukan oleh bagian finance justru dilakukan sendiri oleh bagian purchasing. Hal tersebut terjadi karena kurangnya sumber daya manusia pada perusahaan tersebut.

4. Prosedur pembelian barang di bagian purchasing pada PT. Duraconindo Pratama ada beberapa tahap, yaitu:

c. Menerima daftar permintaan barang.

d. Pemilihan supplier.

e. Pengajuan permintaan penawaran harga.

f. Seleksi supplier berdasarkan kualitas dan harga.

g. Pengeluaran pesanan pembelian/PO (purchase order).

5. Dalam melakukan pembelian barang terdapat beberapa kendala yang dihadapi purchasing seperti schedule pengiriman yang terlambat dari pihak supplier maka berpengaruh pada kegiatan produksi precast lalu barang tidak sesuai PO dan invoice yang diterima disebabkan pihak supplier tidak teliti dalam melakukan pengecekan barang sebelum dikirim. 


\subsection{Saran}

Dari kesimpulan di atas maka penulis dapat memberikan saran kepada PT. Duraconindo Pratama Jakarta sebagai berikut:

1. Perlu adanya penambahan sumber daya manusia di bagian finance demi kelancaran proses pembayaran yang seharusnya dilakukan oleh bagian finance, bukan purchasing.

2. Melihat kendala-kendala yang terjadi maka pihak purchasing harus pintar mengatur waktu dalam melakukan pemesanan barang agar tidak terjadi keterlambatan pengiriman barang. Kemudian untuk meminimalisir kesalahan pengiriman barang yang tidak sesuai PO, maka perlu adanya koordinasi antara pihak supplier dan pabrik (gudang).

\section{Rekomendasi Penelitian Selanjutnya}

Dari hasil penelitian di atas, penulis merekomendasikan untuk penelitian selanjutnya dibahas mengenai aspek sumber daya manusia dan manajemen waktu sehingga kita bisa melihat peran aspek lain dalam meningkatkan kinerja perusahaan.

\section{DAFTAR PUSTAKA}

Arina. 2016. Langkah-Langkah Efektif Menyusun SOP Standard Operating Procedure. Depok: Huta Publisher.

Cahyo, A. D., \& Solikhin, A. (2017). ANALISIS PERANAN PURCHASING TERHADAP PROSES PENGADAAN BARANG DI HOTEL LORIN SOLO. JURNAL PARIWISATA INDONESIA, 10(2). Retrieved from http://jurnal.stpss.ac.id/index.php/JPI/article/view/66

Dewi, W. F. P., \& Wiyani, N. T. (n.d.). Prosedur Pembelian Bahan Baku Secara Kredit Pada PT Burangkeng Maju Teknik. Ejournal-Binainsani.ac.id. Retrieved from http://ejournal-binainsani .ac.id/index.php/JOIA/ article/view/1

Fatimah, Endah Nur. 2015. Strategi Pintar Menyusun SOP Standard Operating Procedure. Yogyakarta: Pustaka Baru Press.

Fatkhudin, A. (2018). SISTEM INFORMASI PENJUALAN DAN PEMBELIAN PADA TOKO ELEKTRONIK LUBADA JAYA KAJEN DENGAN MENGGUNAKAN JAVA. Jurnal Digit, 6(1). Retrieved from https://jurnaldigit.org/index.php/DIGIT/article/view/36 
Hidayat, A. S., \& Witjaksono, R. W. (2017). Perancangan Sistem Erp Dengan Modul Purchasing Dan Inventory Berbasis Odoo 9 Dengan Metode Asap Pada Pt. Aretha Nusantara Farm. eProceedings of Engineering, 3(2), 3483-3490. Retrieved from http://libraryeproceeding.telkomuniversity.ac.id/index.php/engineering/article/vi ew/2267

Prayunantyo, B., \& Supriono, S. (2017). ANALISIS STRATEGI PEMBELIAN DALAM UPAYA PENGADAAN PART MATERIAL IMPORT (Studi pada PT. Indonesia Nippon Seiki). Jurnal Administrasi Bisnis, 50(3), 118-127. Retrieved from http://administrasibisnis.studentjournal.ub.ac.id/index.php/jab/article/view/2013

Sholikhah, I., Sairan, M., \& Syamsiah, N. O. (2017). Aplikasi Pembelian dan Penjualan Barang Dagang pada CV. Gemilang Muliatama Cikarang. Jurnal Teknik Komputer, $\quad 3(1), \quad$ 16-23. $\quad$ Retrieved from http://ejournal.bsi.ac.id/ejurnal/index.php/jtk/article/view/1338/1087

Soemohadiwidjojo, Arini T. 2017. Mudah Menyusun SOP Standard Operating Procedure. Jakarta: Penebar Plus.

Sutarman. 2017. Dasar-Dasar Manajemen Logistik. Bandung: Refika Aditama. 
